\title{
Conceptualising the impact of Culture and Language upon Hospitality Service Management
}

\begin{abstract}
Purpose - To explore the nature and definitions of culture and its relationship to language and cultural sensitivity in hospitality management services.
\end{abstract}

Methodology/Approach - a critical literature review followed by a phenomenological exploratory pilot study, employing Template Analysis.

Findings - Previous studies indicate that the more individuals understand and embrace notions of intercultural sensitivity, then the better they become at being able to recognise and discriminate between cultural differences. Furthermore, as a by-product there is an increased appetite and tendency towards adopting cultural perspectives other than ones' own. However, the operationalisation of this process encourages benchmarking along linear scales, which is problematic and over-simplifies the dynamic and fluid nature of effective cultural transmission. Our findings suggest that rather than there being singular cultural and language constructs: there are cultures, which in places overlap, but elsewhere do not and therefore cannot be placed on universal scales; secondly, the critical success factor is less about linguistic literacy linked to vocabulary and explicit rational comprehension, and more about a pre-emptive cultural interpretive intelligence which identifies emotion and sentiment.

Research limitations/implications - this is largely a conceptual paper, which it is suggested needs further empirical investigation - both longitudinally and on a larger scale.

Practical implications - This perspective moves management, marketing and service delivery away from zero-sum games and transactional exchanges, whether financial, social, or linguistic, towards collective wealth creation, and empowerment - manifest in social cultural capital and the generation of tacit knowledge. The challenge that remains is how this process can be formalised and the tacit and implicit knowledge gained and created can be preserved. 
Keywords- Service Management, Hospitality, Service Delivery, Management, Intercultural Communication,, Language, Template Analysis.

\section{Introduction:}

A crucial aspect of hospitality is grounded in the ability to maintain a level of dialogue and communication that both affirms and is conducive to service excellence. The various ways that this is achieved, through touch points and moments of truth, is subject to cultural differences and the manner in which language is able to facilitate the successful transmission of meaning, aspirations, task completion and social contracts.

Cultural and linguistic elements, where rapport has not been established may however cause some confusion. For instance, Jones and Peppiatt (1996) highlight the different behaviour of guests at Disneyland in Paris in queues for the rides: while some guests waited patiently in line, others accessed rides through ride exits to avoid queuing, unchallenged. Another illumining example is the failure of Wal-Mart in the German retail market, because of a lack of understanding regarding various cultural differences. German customers felt that the American-style greeting of employees in-store was superficial friendliness (Knorr and Arndt, 2003; Witkowski and Wolfinbarger, 2002). Similarly, Martin (2013) describes the "greeters" at JC Penney stores in the USA, which consisted of a model standing with her hands up as if to say, "Stop!" The effects in these examples, through poor hospitality management and as byproduct below standard uniform service delivery, led to confusion and counteracted customers' feelings of satisfaction and hospitality.

Ueltschy et al. (2004) reveal that across cultures due to respondents' bias; in particular the translation, interpretation and meaning of particular linguistic items, some measures of satisfaction and service quality may not be equivalent. Zhang et al. (2008) believe that the cultural dimensions of Hofstede (1980) and Hall (1976) are not reliable for the evaluation of the satisfaction level of individuals, without an appraisal of other factors such as an appreciation of the depth and breath of language. Furthermore, they mention that the SERVQUAL dimensions also are not so reliable; and in future studies, it may be necessary to create a unique service quality measure within cultures - since the individuals from different cultures evaluate services in different ways due to their cultural differences. Put simply, each individual tends to use different dimensions to evaluate their service experience according to their dimensions and definition of service with regard to their values and norms. 
To investigate these further, the authors examine whether national culture is the major cultural influence and whether Hofstede's dimensions are generalizable in particular for the hospitality industry?

In more recent research by Leung et al. (2005) culture has been represented as a multi-layered construct existing at different levels, global, national, organisational and group cultures, which encompass the individual. This research focused on the total processes of groups and society that diverge across countries rather than individuals. This can be considered as the heart of consumer culture.

\section{Variables in Cultural Frameworks}

There are wide-ranging perspectives as to which variables of cultural analysis are of the most significance and relevance. Wilson (2012) undertook a systematic longitudinal and lateral review of social sciences literature, which examines culture through a lens of looking to understand and apply various schools of thought with relevance to a business and management audience.

He observes that business and management literatures' focus is towards the delineation and ascribing of cultural levels. These range from those linked directly to two variables: individuals, and by extension - communities, departments, organisations, regions, industries, nations; and those to culture in abstraction - high/low context, high/low culture, macro/mezzo/micro, East/West, Occident/Orient, and Global paradigms. Central to all of these is the idea that culture is situation specific, dynamic, and is both inclusive and exclusive.

Towards the genesis of this approach, frequently enshrined in business school faculties, Kroeber and Kluckhohn (1952) registered 164 different definitions of Culture. From these, they observe that the essence of culture is present where:

- Members of a system share a set of ideas and especially values

- These are transmitted (particularly through generations) by symbols

- Culture is produced by the past actions of a group and its members

- Culture is learned

- Culture shapes behaviour and influences one' perceptions of the world

- Language is the mediator

Herskovits' (1948) earlier definition of culture that it "is the man-made part of the environment" offers a basis for arguing that the cultural approach to management places an emphasis on 
subjectivity and understanding the impact of created cultural lenses - which shape how people think, feel, and do. Smith and Bond (1998) explain that cultural definitions should include both material objects and social institutions - which points towards a tangible/intangible paradigm, manifest in: implicit, explicit and tacit nodes. In line with this, Schein (1985) as a social psychologist makes a distinction between visible and invisible culture. From this he creates three categories:

1. Assumptions: which are taken for granted and invisible

2. Values: where there is a greater level of awareness

3. Artefacts: the visible face of culture, which is not necessarily decipherable, and often therefore misunderstood. It consists of three manifestations:
a. Physical
b. Behavioural
c. Verbal

Business and management literature has sought to define culture according to systems and more particularly those inside an organisation and outside in the competitive environment, which govern commercial success. Within the field of business and management, Hofstede (1994) investigates what he terms levels of human endeavour - where he groups culture according to a:

National level

Regional and or/ethnic and/or religious level and/or linguistic affiliation level

Gender level

Generation level

Social class level

Organisational or corporate level, according to socialisation by their work (assuming that they are employed)

More recently Hofstede’s work has faced some challenges. McSweeney (2002) challenges the notion of each nation having a distinctive, influential and describable culture. Fiske (2002) critiques Oyserman, Coon and Kemmelmeir's (2002) analysis of national and ethnic differences in individualism and collectivism, which revisited Hofstede's approach - where nations are treated as cultures and culture as a continuous quantitative variable. Fiske argues that such approaches lead to conflations. These conflations he judges ignore contextual specify in norms and values; and reduces culture to explicit, abstract verbal knowledge. 
Echoing these concerns, Holden (2002) comments on the fact that definitions have only continued to increase, rather than there being a polarisation in thought. The authors take this as response to globalisation and intercultural interactions, which are yielding new perspectives. Nevertheless, Kroeber and Kluckohn's elements of essence offer little grounds for contention and so are considered to remain of relevance today, in line with a growing interest in the cultural approach, pregnant in more recent publications. However, central to the research problem is not so much 'what', rather 'how' - with the intention of offering an applied scientific approach to a human phenomenon, leading to a set of guiding principles. Therefore, the central theme taken for this study is the fact that culture relies on iterative and collaborative communication, between participants.

Whilst reflecting on these perspectives and further reviewing related cross-cultural management and anthropological frameworks, Holden (2002) suggests that managing across cultures is:

“... the art of combining varieties of common knowledge through interactive translation. In order to develop this modified concept of cross-cultural management, it will be necessary to come to an understanding of translation both as a process and as an analogy” (p.227).

Within this he also appraises the role of language, concluding that it can be seen metaphorically with

"it's symbolic powers serving to unite people with a sense of common purpose. Seen in this way, language is a very potent expression of company wisdom, lore and vision” (p.227).

As the authors consider the acquisition of cultural intelligence and how this is diffused within managed service delivery, Charlesworth (2008) also contends that education, training and accrued intelligence are central to business and management practice. Globally, business and management education, especially as it is largely conducted in English, contributes towards a convergence in business communication and thought.

Synthesising Charlesworth (2008), Holden (2002), Usunier (2000), Crahay (1996), Hofstede (1994), Schein (1985), Kroeber and Kluckhohn (1952) points: they appear to outline collectively that: 
- Culture is acquired or created - and is transmitted subsequently through teaching and learning

- It exists on multiple levels of abstraction

- The most significant aspects of which are tacit - and therefore are understood best by those who are the most active participants in that collaborative process

- Living breathing language (verbal and non-verbal) and symbolism, this is preserved and exists in the here and now: joins participants together and presents anchors of understanding.

Following a different tack, Smith and Bond (1998) raise interrogative principles designed to underpin cultural understanding. They consider whether:

- There is one best way to run an organisation?

- A native speaker of English communicate effectively to a non-native speaker of English

- Increasing contact between cultures improves intercultural relations

- Human societies eventually merge into one global mega-society? (p.2)

These it is argued encapsulate the key battlegrounds for successful cultural management. Smith and Bond's (1998) central message is that,

"no behaviour and no spoken word has an irreducible objective meaning, Members of different groups or nations place meanings on what goes on around them, and the nuances of these meanings often serve to define identity and to separate one grouping from another" (p.9).

A minor area of contention is their use of 'to' in the second point. Current marketing thinking argues for communications that are two-way and therefore use the word ' with'. Smith and Bond go onto observe that contemporary social psychologist Kurt Lewin (1947) was instrumental in developing Gestalt psychology, which emphasises the way in which perceptions of a stimulus are influenced by its context and social behavioural research should not be conducted in isolation. Services management itself is an amalgam of skills and activities and thus research should be multi-disciplinary.

Rohner (1984) notes that for many parts of the world concepts of society have become synonymous with those of a nation. Rohner (1984) goes further in asserting that the concept of a nation is a Western one, originating from circa the nineteenth century - where boundary 
setting has become more about political expediency, rather than to separate neighbouring societies. Therefore, it is argued that analysing separable sub-cultures linked to national identity, rather than simply nationality, becomes of more significance when attempting to understand culture.

However, whilst apparent inconsistencies between attitudes and behaviour may still exist between individuals across cultures, Ajzen (1988) finds that these will often be explicable due to multiple individual attitudes linked to particular behaviours. In addition, it becomes clear that separating concepts of culture and social systems is problematic. Instead, Smith and Bond (1998) suggest that viewing culture as a relatively organized system of shared meanings is more conductive (p.39).

Here, the most significant unit of cultural analysis is time, which is: contextual, specific, perishable, and dynamic. Furthermore, the concept of time held to be emotional and therefore subjective. This unit of time is a rate-determining step, as defined by collective individuals' implicit and explicit shared value systems.

Therefore, is likely to be a blended or hyphenated construct. For example, national cultural identity may mean more in some contexts than organisational culture. In addition, even with a branded national identity, it may comprise of or be supported by other national identities, as stated by Hofstede (1994) and Minkov and Hofstede (2011). Further to this, the most incisive and meaningful components of culture appear to be rooted in largely implicit drivers, which can lead to complications. The utilisation of these valuable cultural traits also in turn hinges on the successful acquisition of tacit knowledge.

Thus, the literature offers a variety of different interpretations and definitions of culture, where even its variables are subject to critical discussion. This lack of conceptual clarity and academic disagreement does not assist service management practitioners either to understand the theories or applications to industrial practice.

To conclude, a critical success factor rests in managing the transfer of this knowledge. It may be argued that services management focuses primarily on specific, especially technical knowledge (including finance, business administration and human resource management). Perhaps more attention should be given towards understanding tacit cultural clues, especially in customer interactions. Nonaka (1991) contends that, when looking at how tacit knowledge can be converted into the explicit, that it is a process of, "finding a way to express the inexpressible." In addition, it is argued that meaningful tacit knowledge is perishable and 
therefore subject to time. It appears that a way of staving off cultural perishability can be through the transmission of cultural heritage.

\section{Intercultural Competence}

In cross-cultural research, the adjustment towards process of change for each individual is all about learning new behaviours (Black and Mendenhall, 1990; cited by Chang, 2009), and learning new way of communication (Vaener and Beamer, 2010).

Bhawuk and Brislin (1992:416) state that cross-cultural sensitivity is crucial for successful interactions with people from cultures other than one's own, ranging from job performance during interactional assignments to tourism, immigration, and refugee resettlement. They suggest the following key to success in intercultural contexts: "people needs to be interested in other cultures, be sensitive enough to notice cultural differences, and then also be willing to modify their behaviour as an indication of respect for the people of cultures" (cited by Greenholtz, 2005).

Friedman and Antal (2005) indicate that intercultural or cross-cultural competence in the skill to think and act in appropriate ways with people from other cultures. Intercultural effectiveness, the general assessment of the ability and skill for effective intercultural communication (Cui and Awa, 1992; Hammer et al., 1979). However, prior research conducts the fact that some complains towards poor service occur because of lack of communication skill or perhaps less knowledge of host native language among customers.

Schmidt and Hunter (2000) define intercultural intelligence, is a specific form of intelligence focused on abilities to hold reason and behave effectively in situations characterised by cultural diversity.

Earley et al. (2007) stress that cultural intelligence, the ability and skill to gather, interpret, and act upon different cues to function effectively across different cultural settings.

Furthermore, intercultural intelligence is all about acknowledges about practical realities of globalisation and multiculturalism. Ang et al. (2007) state that behavioural CQ reflects the ability to exhibit appropriate verbal and non-verbal actions when interacting with people from vary cultures. He states Hall argument in this regard, which mental ability for cultural understanding and motivation must be complemented with the skills to demonstrate appropriate verbal and non-verbal actions, based on cultural values of specific settings (Hall, 1959). CQ has been introduced as a tool to understand the variety of cultural and how its work within home culture and host culture interaction. As, Earley and Ang (2003)mention, it is the 
skill to encode and decode emotions in the home culture does not automatically transfer to unfamiliar cultures.

In addition, Bhaskar-Shrinivas et al. (2005) argue that intercultural encounters, can be named as cultural adaptation, when individual relocate to new and unfamiliar cultures, they often experience stress as a result of seeing new norms and behaviours, now the idea and concept of cultural adaptation will be raised. This adaptation includes the socio-cultural sense of adjustment and psychological feeling of wellbeing (Searle and Ward, 1990); (cited by Ang et al., 2007).

As Stauss and Mang (1999) stress that intercultural service encounters (ICSEs) is all about interactions between customers and service providers from different cultures. The most mentioned challenges in intercultural service encounters are language barriers and differences in expectations among customers and service providers. Tam et al. (2014) also highlight that the language barriers are definitely the most challenging. Sometimes service provider prefer don't serve customers, when they feel there is a language barrier. Communications and differences in expectations, norms and behaviour, and of course the language barrier is an issue to provide satisfaction to customers.

Research on intercultural interaction in service encounters often leads researchers to intercultural communication, Gudykunst (2002:179) defines intercultural communication as a "communication which happened between people from different national cultures, and many scholars limit it to face-to-face communication”.

The essence of service management is the interaction between customer and provider, which relates to both organisational success and satisfaction. Therefore, successful service organisations need to be aware of the role that culture plays in enhancing this critical interaction, preventing misunderstandings and helping to make it more comfortable for all those involved. Research such as that undertaken by Geertz (1973) and Katriel and Philipsen (1981) indicate that within the essence of culture a fabric of meaning is transmitted through language and cocreated symbolic meanings.

\section{Communications and Culture}

As communication, propagation and proselytization of culture, necessitates the use of language, this will now be considered in more detail. Whilst complicated, diverse and variegated, language provides insight into how humans approach culture. In support of language being of significance, Usunier (2000), when looking at marketing across cultures, adopts an approach 
considering firstly English in particular, as it is the worldwide language of business. This is in further support of the authors decision to undertake this study in English. Secondarily foreign languages are considered in tandem - as collectively they all express culturally specific patterns, which are embedded in contextual situations. Literature and data searches point to the strongest global brands being known according to strong linkages with English language text and English derivatives, shaped by non-English language natives. Examples of colloquial terms are: Americanisms, BBC English, Business English, Engrish, Indian English and Jamaican Patois amongst others. Furthermore, following Usunier's observations, this study is conducted in English and it also considers how 'other' languages may shape the understanding of experts.

\section{Exploratory Study Method}

Following our challenge of the normative literature in not being able to address the disconnect fully between the intrinsic and extrinsic factors associated with management, service delivery, and marketing within an overarching dynamic cultural paradigm: a qualitative pilot study was undertaken. The method employed was Template Analysis, which is a relatively recent development that has emerged from the more structured approaches outlined in Grounded Theory and interpretative Phenomenological Analysis (IPA) (Waring and Wainwright, 2008). King (1998:18) defines Template analysis (TA) as "one of thematic analysis style that balances a relatively high degree of structure in the process of analysing textual data with the flexibility to adapt it to the needs of a specific study”. TA mostly been used for analysing data from individual interviews, however, some researchers like Kent (2000) and Brennan (2012) use it for questionnaires and analysing participant observation King (2012:426). TA can be interpreted as approach that helps researchers to "uncover the real beliefs, attitudes, values and so on of the participants in their research” (cited in King, 2012:426).

Further areas of research that employ TA include, organisational research such as management and business (e.g. Kenny and Briner, 2010; McDowall and Saunders, 2010; Altinay et al., 2014), health (Howard et al., 2008), education (Au, 2007), sports science (Nash and Sproule, 2009), tourism (Andriotis, 2010); (cited in King, 2012:427). TA studies vary in terms of size, from a single autobiographical case (King, 2008) to very large studies that may be considered large in qualitative terms like 81 interviews by Donnelly, 2008), (cited in King, 2012:427). 
The TA method offers the ability to enhance the coding process alongside making coding refinements and revisions during data analysis. Furthermore, King (2004) examines three positions when starting out on the research: (1) having pre-define codes/a priori codes based on the theoretical position of the research, (2) developing codes after some initial exploration of the data, (3) taking a half way position, which also incorporates initial codes. In TA the key decision is when the initial template begins to develop and is formalised - and this is judged to have happened following the clustering of preliminary codes, to generate meaningful groups that "within hierarchical and lateral relations between themes [findings] can be defined" (King, 2012:435-436).

King et al., (2004) mention that although template analysis makes use of codes and coding of data it is not as prescriptive as Grounded Theory, as is not wedded to its realist methodology. In fact it can be used within a range of epistemological positions and thus can be useful to a large number of researchers. In other words, when template analysis is used broadly within a phenomenological approach it is very similar to IPA; but with the main difference being the use of 'a priori' codes in template analysis and the balance within different case analysis. Crabtree and Miller (1999:167) highlight on their early stage of template analysis that: "researchers can develop codes only after some initial exploration of the data has taken place, using an immersion/ crystallisation or editing organising style. A common intermediate approach is when some initial codes are refined and modified during the analysis process”.

In this regard, King (2012:447) names the key advantages of TA as being a highly flexible approach that can be modified for the needs of any study and a "welcoming approach for those who prefer to use a phenomenological and experiential approach to organisational their research" - particularly because the "discipline of producing the template forces the researcher to take a systematic and well-structured approach to handling the data”.

\section{Sample}

Structured interviews employing purposive sampling were undertaken in New York, with 36 numbers of participants within hotel settings, and ranging from management, consumer-facing employees, and customers. Purposive sampling was used via an initial screening process of informal exploratory screening questions - to ensure that sufficient cultural, national, linguistic and diversity was achieved; alongside varied experiences associated with travel, intercultural interactions, and the consumption and delivery of hospitality. 
Maxwell (1997:87) defines purposive sampling as a type of sampling in which "particular settings, persons or events are intentionally selected for the important information they can provide that cannot be developed as well from other choices” (cited inTeddlie and Yu, 2007). Purposive sampling is designed to provide a sample that will answer questions under investigation and can be generalised, to some extent, to a wider external context or population.

Purposive sample is originally designed to choose a small number of cases that will be produced the most information about a specific phenomena as well as leads to greater depth of information from a smaller number of carefully selected cases (Teddlie and Yu, 2007; Patton, 2002). Mason (2006) also states that sampling frame in purposive is a resource from which researchers can select smaller sample. As Patton (1990b:176) highlights “all cases that meet some predetermined criterion of importance” should be included.

Scenario-based open-ended questions that sought to explore instances where language and culture were vehicles and catalysts for critical success factors were used - regardless of whether they were conducive or counter-productive.

\section{Findings and Discussion}

The most noticeable finding, derived from the empirical data, is how different cultural frames of reference, used both for benchmarking and as guiding principles, affect working definitions, expectations, aspirations, and interactions.

With regards to what is perceived to be New York culture: customers as being, "rude and pushy" and "so fast compared to other places", define this. General managers in the service and hospitality sector, working in New York, define hospitality as the ability to: "be flexible and acceptable”, and "provide the feeling to the customer of being at home”. Here the authors take the definition of New York culture and the culture of hospitality professionals to be linked. In doing so, they argue that both are culturally symbiotic; and a form of cultural osmosis occurs.

From this premise, and if it is taken on face value that hotel staff were able to achieve their aims and objectives to a degree: the fact that customers were surveyed in a hotel setting, which was judged to be flexible, accepting, and welcoming - and yet still saw New York culture as being rude and pushy suggests several possible conclusions. 
It is felt that an assumption of the hotel environment being totally different from that of New York in general and therefore non-representative, or insufficiently experiential to prime and influence customers at the time of surveying is unlikely. Rather, the fact that the hotels in which the customers had been surveyed had achieved success in delivering cultural rapport and surrogacy led customers not to see them as being New Yorker. This poses challenges to workers because it might be assumed that good service delivery would directly translate into positive cultural ambassadorship for New York, or elicit a moderating statement excluding the hotel, when customers expressed their negative views about New York.

In stark contrast to the views of general managers, some customers believe that "hospitality is a robotic industry”, where in general many staff are just following what they have been told to do, and they do not know what needs to done if something goes wrong. However, no direct link was made by customers between these perceptions and their current experiences. Again, following the same train of thought in line with first set of observations, the authors consider whether successful service delivery and cultural rapport might in fact be hygiene factors, which therefore mask their value and resonance, unless there is breakdown in transmission.

Managers do highlight some difficulties concerning host-guest interactions; and list the following as major factors: accent, language barrier, and, perceptions towards services and delivery. Interestingly the cultural awareness among hospitality staff regarding Jewish and Japanese norms, values, and practices did elicit a positive and explicit response towards their services.

Japanese customers mentioned their different practice regarding tipping. Whilst accepted and encouraged culturally in the USA, its meaning in Japan is different and would be seen of as being disrespectful. In fact Japanese customers expressed no negative views about US tipping culture in the US, and instead chose to speak favourably about staff in New York's hotels and their ability to understand Japanese culture. The authors do concede that perhaps for cultural reasons the Japanese guests may not have wished to express negative views; and the mention of tipping may be a subtle and subversive way of highlighting their own perceived cultural superiority and diplomacy. Anecdotally in a previous study, authors found that one senior hotel manager from a global chain mentioned Japanese tourists complaining only after their stay, via a travel agent. 
One participant, a customer originally from Japan but living in NYC for almost twenty-five years mentioned that although New York is famous for being a " 'melting pot'...I think it is more of a 'mosaic' base and each group is living with each other and accepting each other, but not melting, and because of this people are more tolerance towards each other.”

\section{Reflective Discussions linked to the literature}

It seems that intercultural and cultural diversity has been accepted in most research area namely marketing, advertising and management. But there is a lack of research and a literature gap concerning the relationship between guests and host and their language barriers towards cultural understanding in multicultural societies and hospitality.

Sharma et al. (2009) argue that ICSE (intercultural service encounters) provides an opportunity to the new immigrants to learn about their host culture in order to adapt and integrate better, although, tourists may not feel to integrate because of their limited interaction with the host culture.

Despite the fact that Hofstede's framework has been used in all areas of research, the main problem arises when it is applied to customer behaviour in today's multicultural society. He categorised all Middle East countries in one group, which suggests a generalistic approach. For instance, Iran, Turkey and the United Arab Emirates are quite distinct from one another and based on these differences the behaviour and expectations of customers will differ from each other. Similarly, he grouped all Arab countries together, which represents another issue since these cultures also have different behaviours: they speak different versions of Arabic and the way of communication and customs are also different from each other (Sobh, Belk and Wilson, 2013).

With this in mind, the authors assert that whilst Hofstede outlines a framework for benchmarking national cultures and identities on a macro level, short falling sin his findings are that: firstly, they are also posited to apply on a micro level to intercultural communication statically; secondly, between cultures and national identities (which are used interchangeably) a chosen language and mode of communication is symmetric, whilst cultural transmission may exhibit signs of asymmetry; and thirdly, that culture evades the dynamism of innovation, collective learning, reciprocity, and dissonance reduction of conscious and unconscious bias through change.

In contrast, our findings suggest that rather than there being singular cultural and language constructs: there are cultures, which in places overlap, but elsewhere do not and therefore 
cannot be placed on universal scales; secondly, the critical success factor is less about linguistic literacy linked to vocabulary and explicit rational comprehension, and more about a cultural interpretive intelligence which identifies emotion and sentiment.

This perspective moves management, marketing and service delivery away from zero-sum games and transactional exchanges, whether financial, social, or linguistic, towards collective wealth creation - manifest in social cultural capital and the generation of tacit knowledge.

In short, service delivery is about facilitating an enhanced cultural experience, rooted in universal exemplars of excellence; judged according to human bonds of self-actualisation, for strategic and commercial gains. The challenge that remains is how this process can be formalised and the tacit and implicit knowledge gained and created can be preserved.

Conceptualisation of Cultural Sensitivity 


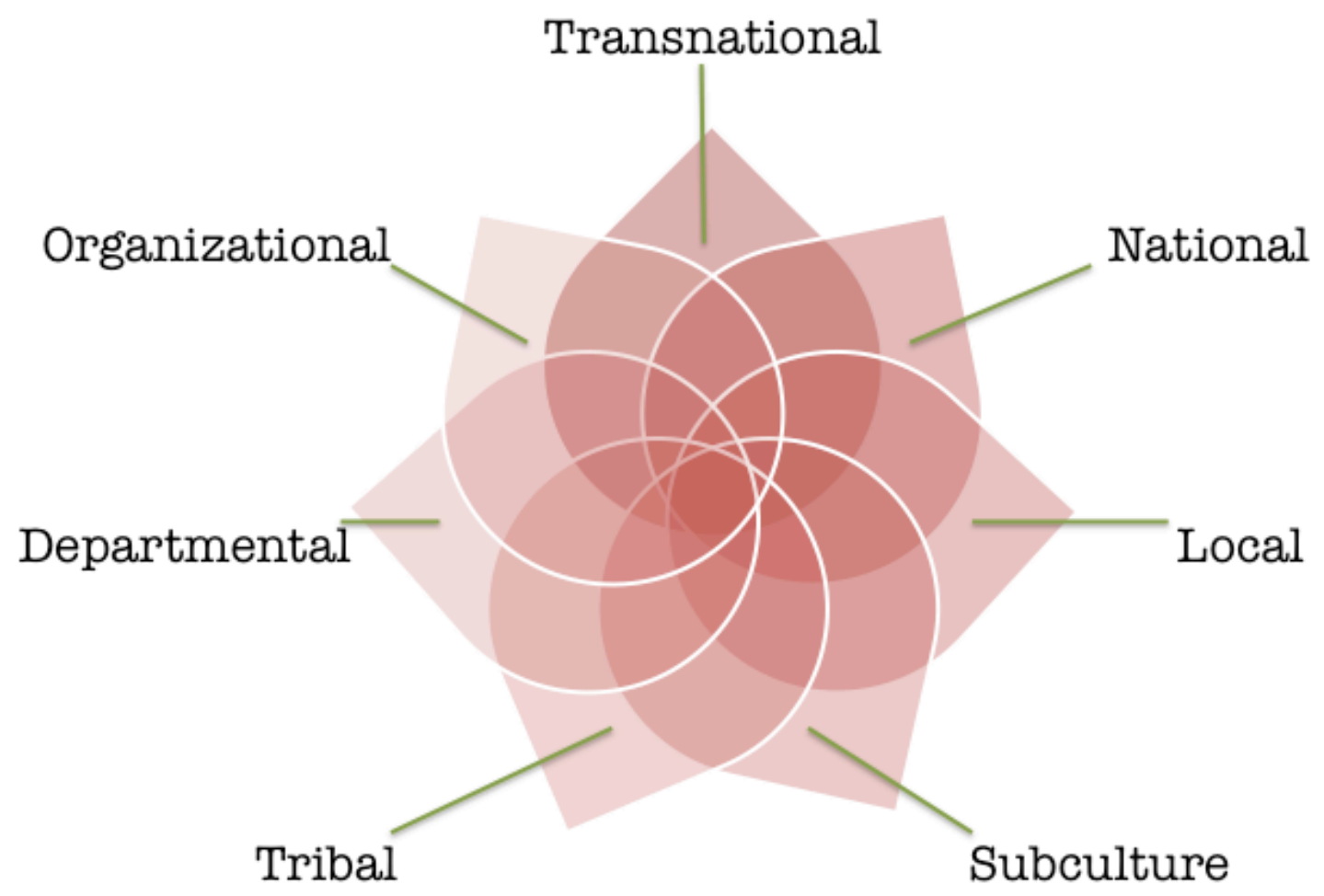

Figure 1. “Cultural Petals”, (Wilson, 2013)

Following earlier assertions that it is more conducive to view culture in the plural and that cultures cannot be judged along one universal scale, the authors adopt the more recent model presented by Wilson (2013). The diagram should be viewed as a Venn diagram model with 7 'cultural petals' variables of transnational, national, local, subculture, tribal, departmental and organizational culture, which merges personal and firm cultures . In some situations, only one cultural frame of reference may predominate, for example local customs. However, in other instances, several variables may work in tandem or against each other. Here, there may be a subculture, which draws from local customs; or a departmental culture, which clashes with organizational culture.

Wilson (2011), and Wilson and Liu (2012) also provide a broader cultural perspective, outlining a framework that charts a macro-process of cultural understanding within a businesscultural context, in an attempt to reconcile differences in global brand literature 


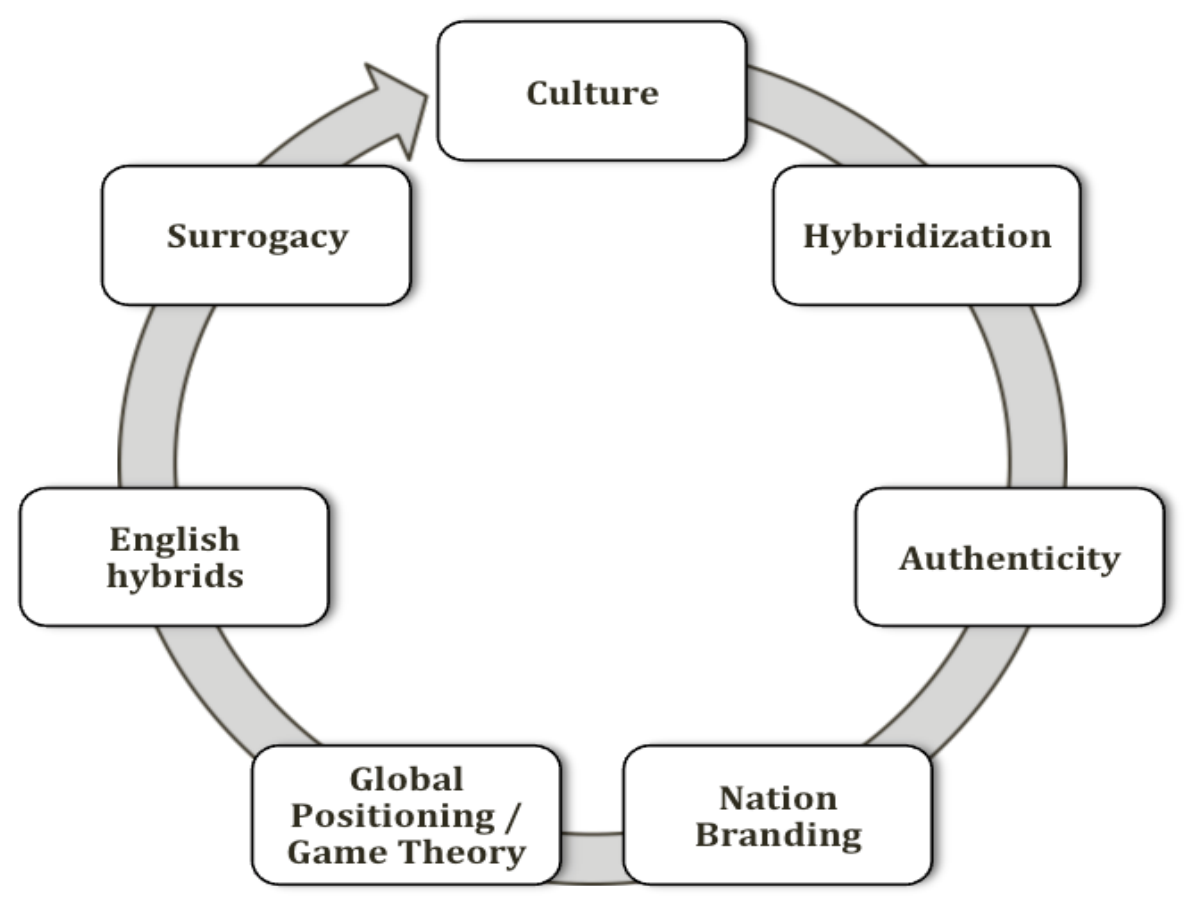

Figure 2. C.H.A.N.G.E.S. model (Wilson, 2011)

The position adopted here in the 'CHANGES' model is that intercultural analysis, through contextualising factors that govern stakeholder interactions, should be mapped out according to: cyclical, dynamic and time specific communication networks. To this end, culture is transmitted through the subsequent stages of the model, with these stages representing critical rate-determining evaluative factors.

As has been discussed, English is the lingua franca of business and key to cultural transmission and understanding. But, as it is as second language to many more than hold it as a native tongue, English language itself demonstrates continual evolution - increased by ‘non-natives’.

Moving discussions forward, the authors suggest that more empirical work is needed to develop scales which can qualify and quantify where and how these factors interact on interdependent positive and negative scales. Furthermore, attempts should be made to ascribe where cultural efficacy and power lies with respect to staff and customers; and how this is manifest in terms of a set of prescribed outcomes.

A further sentiment expressed by the authors is that such work should bridge the gap between literature and studies that seek to adopt either customer or service provider perspectives. 


\section{Conclusions}

Whilst complicated, diverse and variegated, language provides insight into how humans approach culture. There are varying perspectives as to which unit of cultural analysis is of the most significance and relevance. Observations in business and management literature point to the delineation and ascribing of cultural levels. These range from those linked directly to two variables: individuals, and by extension - communities, departments, organisations, regions, industries, nations; and those to culture in abstraction - high/low context, high/low culture, macro/mezzo/micro, East/West, Occident/Orient, and Global paradigms. Central to all of these is the idea that culture is situation specific, dynamic, and is both inclusive and exclusive.

Previous studies indicate that the more individuals understand and embrace notions of intercultural sensitivity, then the better they become at being able to recognise and discriminate between cultural differences. Furthermore, as a by-product there is an increased appetite and tendency towards adopting cultural perspectives other than ones' own. However, the operationalisation of this process encourages benchmarking along linear scales, which is problematic and over-simplifies the dynamic and fluid nature of effective cultural transmission. For example, in many developed countries ethnic restaurants are becoming more popular as disposable income grows. They may fulfil a need for culinary and novelty, so the service and food should be different, but not uncomfortably so for the diner.

Our findings suggest that rather than there being singular cultural and language constructs: there are cultures, which in places overlap, but elsewhere do not and therefore cannot be placed on universal scales; secondly, the critical success factor is less about linguistic literacy linked to vocabulary and explicit rational comprehension, and more about a cultural interpretive intelligence which identifies emotion and sentiment.

This perspective moves management, marketing and service delivery away from zero-sum games and transactional exchanges, whether financial, social, or linguistic, towards collective wealth creation, and empowerment - manifest in social cultural capital and the generation of tacit knowledge. However, the challenge that remains is how this process can be formalised and the tacit and implicit knowledge gained and created can be preserved. Perhaps greater 
conceptual understanding can better inform service organisations whose existence depends upon ensuring that cultural or linguistic misunderstandings do not affect either customer satisfaction or staff morale. Thus, cultural sensitivity training can, hopefully, be made more effective and linked to organisational goals.

This is largely a conceptual paper, which it is suggested needs further empirical investigation both longitudinally and on a larger scale. With this in mind, more empirical work is needed to develop scales which can qualify and quantify where and how these factors interact on interdependent positive and negative scales. Furthermore, attempts should be made to ascribe where cultural efficacy and power lies with respect to staff and customers; and how this is manifest in terms of a set of prescribed outcomes. 


\section{$\underline{\text { References }}$}

Ajzen, I. (1988), Attitudes, Personality and Behavior, Milton Keynes, UK: Open University Press.

Ang, S., Van Dyne, L., Koh, C., Ng, K. Y., Templer, K. J., Tay, C.; andChandrasekar, N. A. (2007), Cultural Intelligence: Its Measurement and Effects on Cultural Judgment and Decision Making, Cultural Adaptation and Task Performance, Management and Organization Review, Vol.3, No.3, 335-371.

Bhaskar-Shrinivas, P., Harrison, D. A., Shaffer, M. A.; andLuk, D. M. (2005), Input-based and time-based models of international adjustment: Meta-analytic evidence and theoretical extensions, Academy of management Journal, Vol.48, No.2, 257-281.

Bhawuk, D. P.; andBrislin, R. (1992), The measurement of intercultural sensitivity using the concepts of individualism and collectivism, International Journal of Intercultural Relations, Vol.16, No.4, 413-436.

Black, J. S.; andMendenhall, M. (1990), Cross-cultural training effectiveness: A review and a theoretical framework for future research, Academy of Management Review, Vol.15, No.1, 113-136.

Chang, W.-W. (2009), Schema adjustment in cross-cultural encounters: A study of expatriate international aid service workers, International Journal of Intercultural Relations, Vol.33, No.1, 57-68.

Charlesworth, Z.M. (2008), “Learning styles across cultures: suggestions for educators”, Education and Training, Vol. 50 No. 2, pp. 115-127.

Crabtree, B. F.; andMiller, W. L. (1999), Using codes and code manuals: a template organizing style of interpretation, Doing qualitative research, Vol.2, 163-177.

Crahay, M. (1996), L'artet la science de l'enseignement, Bruxelles: Editions Labor.

Cui, G.; andAwa, N. E. (1992), Measuring intercultural effectiveness: An integrative approach, International Journal of Intercultural Relations, Vol.16, No.3, 311-328.

Derrida, J. (2000a), Hostipitality, Angelaki: Journal of Theoretical Humanities, Vol.5, No.3, 3-18.

Earley, P.; andAng, S. (2003), Cultural intelligence : individual interactions across cultures Ed., Stanford, Calif.: Stanford University Press. 
Earley, P., Murnieks, C.; andMosakowski, E. (2007), Cultural intelligence and the global mindset, Advances in international management, Vol.19, 75-103.

Fiske, A.P. (2002), “Using Individualism and Collectivism to Compare Cultures - A Critique of the Validity and Measurement of the Constructs: Comment on Oyserman et al. (2002)”, Psychological Bulletin, Vol.128 No.1, pp.78-88.

Friedman, V. J.; andAntal, A. B. (2005), Negotiating Reality A Theory of Action Approach to Intercultural Competence, Management Learning, Vol.36, No.1, 69-86.

Geertz, C. (1973), 1973The Interpretation of Cultures, New York: Basic.

Greenholtz, J. F. (2005), Does intercultural sensitivity cross cultures? Validity issues in porting instruments across languages and cultures, International Journal of Intercultural Relations, Vol.29, No.1, 73-89. doi: 10.1016/j.ijintrel.2005.04.010

Gudykunst, W. B. (2002), Intercultural communicationIn W. B. Gudykunst andB. Mody (Eds.), Handbook of international and intercultural communication (pp. 179-182). Thousand Oaks, CA: Sage.

Hall, E. T. (1959), The silent language Ed., Garden City, N.Y.: Doubleday.

Hall, E. T. (1976), Beyond culture Ed., Garden City, N.Y.: Anchor Press.

Hammer, M. R., Gudykunst, W. B.; andWiseman, R. L. (1979), Dimensions of intercultural effectiveness: An exploratory study, International Journal of Intercultural Relations, Vol.2, No.4, 382-393.

Herskovits, M.J. (1948), Man and his Works: The Science of Cultural Anthropology, New York: Knopf.

Hofstede, G. (1994), Culture and organizations: Intercultural cooperation and its importance for survival - software of the mind, London: Harper Collins.

Hofstede, G. H. (1980), Culture's consequences : international differences in work-related values Ed., Beverly Hills, Calif.: Sage Publications.

Holden, N. J. (2002), Cross-Cultural Management - A Knowledge Management Perspective, Pearson Education Ltd., Harlow, Essex.

Jones, P.; andPeppiatt, E. (1996), Managing perceptions of waiting times in service queues, International Journal of Service Industry Management, Vol.7, No.5, 47-61. 
Katriel, T.; andPhilipsen, G. (1981), “What we need is communication”:“Communication” as a cultural category in some American speech, Communication Monographs, Vol.48, No.4, 301-317.

King, N., Cassell, C.; andSymon, G. (2004), Using templates in the thematic analysis of texts, Essential guide to qualitative methods in organizational research, 256-270.

Knorr, A.; andArndt, A. (2003), Why did Wal-Mart fail in Germany? Ed.: Inst. für Weltwirtschaft und Internationales Management.

Kroeber, A.L. and Kluckhohn, C. (1952), Culture: A critical review of concepts and definitions, Cambridge, MA: Harvard University Press. Quoted in: Encyclopæedia Britannica (2000).

Leung, K., Bhagat, R. S., Buchan, N. R., Erez, M.; andGibson, C. B. (2005), Culture and international business: recent advances and their implications for future research, Journal of International Business Studies, Vol.36, No.4, 357-378.

Lewin, K. (1947), “Group decision and social change”, in T.M. Newcomb and E.L. Hartley (Eds.), Readings in Social Psychology, New York: Holt.

Martin, C. L. (2013). Ladies and gentleman: this is a service: opportunities to revisit and refocus? Paper presented at the 6th International Conference on Service Management, Cyprus.

McSweeny, B. (2002), "Hofstede's model of national cultural differences and their consequences: A triumph of faith - a failure of analysis”, Human Relations, Vol.55 (1), pp.89-118.

Minkov, M. and Hofstede, G. (2011), Cross Cultural Management: An International Journal, Vol.18 No.1, pp.10-20.

Nonaka, I. (1991), “The Knowledge Creating Company”, Harvard Business Review, Managing for the long term, July-Aug 2007.

Oyserman, D., Coon, H.M. and Kemmelmeier, M. (2002), "Rethinking individualism and collectivism: Evaluation of theoretical assumptions and meta-analysis”, Psychology Bulletin, Vol.128, pp.3-72.

Rohner, R. (1984), “Toward a conception of culture for cross-cultural psychology”, Journal of Cross-Cultural Psychology, 15, pp.111-138. 
Schein, E.W. (1985), Organizational Culture and Leadership, Boston, MA: Harvard Business School Publishing Corpn.

Schmidt, F. L.; andHunter, J. E. (2000), Select on intelligenceIn E. A. Locke (Ed.), The blackwell handbook of organisational principles (pp. 3-14). Oxford: Balckwell.

Searle, W.; andWard, C. (1990), The prediction of psychological and sociocultural adjustment during cross-cultural transitions, International Journal of Intercultural Relations, Vol.14, No.4, 449-464.

Sharma, P., Tam, J. L. M.; andKim, N. (2009), Demystifying Intercultural Service Encounters: Toward a Comprehensive Conceptual Framework, Journal of Service Research, Vol.12, No.2, 227-242. doi: 10.1177/1094670509338312

Smith, P.B. and Bond, M.H. (1998), Social Psychology Across Cultures, (2 ${ }^{\text {nd }}$ Ed.), Harlow, Essex: Prentice Hall Europe.

Sobh, R., Belk, R.W. \& Wilson, J.A.J. (2013), “Home and Commercial Hospitality Rituals in Arab Gulf Countries”, Marketing Theory,December, 13 (4), pp.443-463.

Stauss, B.; andMang, P. (1999), Culture schocks in inter-cultural service encounter?, Journal of Services Marketing, Vol.13, No.4/5, 329-346.

Tam, J., Sharma, P.; andKim, N. (2014), Examining the role of attribution and intercultural competence in intercultural service encounters, Journal of Services Marketing, Vol.28, No.2, 159-170. doi: 10.1108/jsm-12-2012-0266

Trommsdorf, G. and Dasen, P.R. (2001), “Cross-cultural study of education”, in Smelser, N. and Bates, P. (Eds), International Encyclopedia of the Social and Behavioural Sciences, Amsterdam: Elsevier, pp. 3003-7.

Ueltschy, L. C., Laroche, M., Tamilia, R. D.; andYannopoulos, P. (2004), Cross-cultural invariance of measures of satisfaction and service quality, Journal of Business Research, Vol.57, No.8, 901-912.

Usunier, J-C. (2000), Marketing Across Cultures, (3 ${ }^{\text {rd }}$ Ed.), Harlow, Essex: Prentice Hall Europe.

Vaener, I.; andBeamer, L. (2010), Intercultural Communication in the Global Workplace Ed.: McGraw-hill Education. 
Waring, T.; andWainwright, D. (2008). Innovative developments in the use of template analysis: Two comparative case studies from the field. Paper presented at the 7th European Conference on Research Methodology for Business and Management Studies: Ecrm 2008.

Wilson, J.A.J. (2013), "Why culture matters in marketing and where?”, The Marketeers, June,Indonesia: MarkPlus Inc., pp.78-84.

Wilson, J.A.J. (2012), The Brand, Culture \& Stakeholder-based Brand Management phenomenon: An International Delphi Study, PhD Thesis, Brunel University London http://bura.brunel.ac.uk/handle/2438/6557

Wilson, J.A.J. (2011), “New-School Brand Creation and Creativity - lessons from Hip-Hop and the Global Branded Generation”, Journal of Brand Management, Vol.19 Issue 2, Oct/Nov, pp.91-111.

Wilson, J.A.J. \& Liu, J. (2012), "Surrogate Brands - The pull to adopt and create hybrid identities - via sports merchandise", International Journal of Sport Management and Marketing, Vol.11 No.3/4, pp.172-192.

Witkowski, T. H.; andWolfinbarger, M. F. (2002), Comparative service quality: German and American ratings across service settings, Journal of Business Research, Vol.55, No.11, 875-881.

Zhang, J., Beatty, S. E.; andWalsh, G. (2008), Review and future directions of cross-cultural consumer services research, Journal of Business Research, Vol.61, No.3, 211-224. 